\title{
An experimental and numerical investigation of mechanical properties of glass fiber reinforced epoxy composites
}

\author{
Satnam Singh ${ }^{*}$, Pardeep Kumar, S.K. Jain \\ Department of Mechanical Engineering, Ambala College of Engineering and Applied Research, Devsthali, Ambala, India \\ *Corresponding author. Tel: (+91) 132 2714328; E-mail: satnam.mmu@ gmail.com
}

Received: 23 November 2012, Revised: 28 December 2012 and Accepted: 07 January 2013

\section{ABSTRACT}

Composites are one of the most advanced and adaptable engineering materials. The strength of any composite depends upon volume/weight fraction of reinforcement, L/D ratio of fibers, orientation angles and other factors. The present work focuses on determination of mechanical properties of pure epoxy and random oriented glass fiber (mat) reinforced epoxy at $10 \%$ and $20 \%$ weight fractions of glass fibers. The test specimens were prepared and tested according to ASTM standards. The experimental results revealed that with increase in weight fraction of reinforcement, the tensile strength and flexural strength increased by $14.5 \%$ and $123.65 \%$ for $20 \%$ glass reinforced composites over pure epoxy. The numerical results obtained were in good agreement to the experimental results. However increased reinforcement increases the brittleness of material which may results in low impact strength. This study further can be used to optimize the weight fraction of glass fibers, to achieve a combination of strength without compromising the impact strength of composites. Copyright $(\underset{2}{2013}$ VBRI press.

Keywords: Fiber reinforced plastic; polymer composites; tensile strength; flexural strength; finite element analysis; weight fraction.

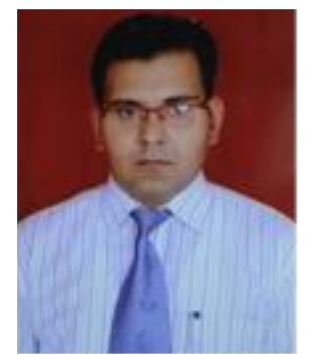

Satnam Singh obtained his Bachelor's Degree in Mechanical Engineering from Kurukshetra University and Masters Degree in Manufacturing Systems (Mech. Engg.) from Maharishi Markandeshwar University, Mullana. He is presently working as Asst. Professor in Mechanical Department of Ambala College of Engineering, Ambala. He is presently working in the area of polymeric resin synthesis, modification and composite processing and characterization. He has published number of research papers in various international and national journals.

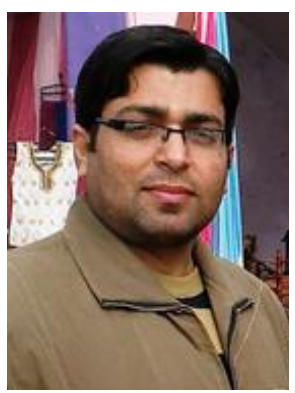

Pardeep Kumar obtained his Bachelor's Degree in Mechanical Engineering from Kurukshetra University and Masters Degree in Mechanical from NIT Kurukshetra. He is presently pursuing Doctorate in the field of Industrial engineering from NIT Kurukshetra. $\mathrm{He}$ is working as Assistant Professor in Mechanical Department of Ambala College of Engineering, Ambala. He is presently working in the area of Reliability and six sigma. He has published number of research papers in various international and national journals.

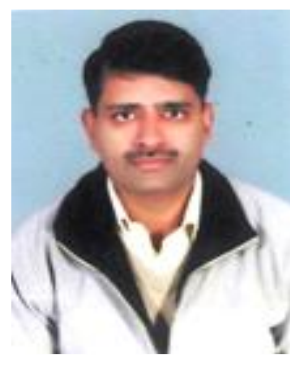

Sanjiv Kumar Jain holds a Bachelor's Degree in Mechanical Engineering from The Institution of Engineers, Calcutta, and Master's Degree in Industrial Engineering from Guru Nanak Dev Engineering College, Ludhiana, India. Presently, he is working as Associate Professor in Department of Mechanical Engineering at Ambala College of Engineering \& Applied Research, Ambala, Haryana (India). His main research area is ISO 9000 and Total Quality Management.

\section{Introduction}

For years, composite materials have growing applications in different industries. Composite is a mixture of two or more constituents/materials (or phases) with different physical/chemical properties at the macroscopic or microscopic scale. In general composites have two or more constituents, fiber and matrix. Composites are classified by the geometry of the reinforcement: particulate, flake, and fibers or by the type of matrix: polymer, metal, ceramic, and carbon. The basic idea of the composite is to optimize material properties of the composite, i.e., the properties of the matrix are to be improved by incorporating the reinforcement phase. Fibers are the principal load-carrying constituents while the surrounding matrix helps to keep 
them in desired location and orientation and also act as a load transfer medium between them [1]. The effective properties of the fiber reinforced composites strongly depend upon the geometrical arrangement of the fibers within the matrix [2]. This arrangement is characterized by the volume fraction, the fiber aspect ratio, fiber spacing parameters and orientation angles of fibers. Thermoplastic composites reinforced with long fibers, short fibers and mat (fabric) of natural and synthetic fibers like hemp, jute banana, glass, carbon, kevlar etc are used in a variety of applications such as aerospace elements, automotive parts, marine structures, structural members and antivibration applications due to their combined properties of resilience, creep resistance, high strength to weight and stiffness to weight ratios, corrosion resistance and good damping properties [3, 4, 5]. Due to inherent advantages of composites over traditional materials like metals, their utilization over the last decade increased many folds in the field of design of many engineering and structural components [6]. Many researchers have analytically and experimentally investigated [7-12] the mechanical properties (tensile, flexural, toughness, fatigue etc.) of FRP composites and other used finite element analysis [13-17] to predict the behavior of FRP and their mechanical properties. Ghassemieh [18, 19] developed a micromechanical model to understand the behavior of fiber and particulate reinforced polymeric composites. This model was used to simulate stress distribution and to identify the maximum stress concentrations locations. The interfacial stresses evaluated by model were compared with the well known shear lag and modified shear lag models. Horsta et al. [20] developed a finite element model to predict the interfacial tensile and shear stress and validated experimentally. Perfect bonding between fiber and matrix was considered. Caporale et al. [21] examined the behavior of unidirectional fiber-reinforced composites with imperfect interfacial bonding with the aid of finite element method. However a few efforts were made to relate the experimental results of mechanical properties of FRP with the finite element analysis results while considering the isotropic behavior of composites. The main advantage of using finite element analysis is to generate the quantitative data about the failure morphology of the composites and to understand the deviation of results from the experimental results. In present work an attempt is made to relate the experimental and numerical results of tensile and flexural tests by considering the isotropic behavior of composites. The values of poisson's ratio (v) and young modulus of elasticity (E) were determined experimentally and same were used in finite element analysis. The experimental results were reproduced by applying the same boundary and loading conditions in Ansys 12 (non commercial version) and comparisons were made.

\section{Experimental}

\section{Materials}

The composite material used in this research was manufactured using plain weave E-glass fabrics of $0.3 \mathrm{~mm}$ thickness as reinforcement. Glass fiber is a lightweight, extremely strong, and robust material. Although strength properties are somewhat lower than carbon fiber and it is less stiff but it is typically far less brittle and the raw materials is much less expensive. The matrix material was epoxy resin ( $R$ 101) and standard hardener ( $H$ 101) supplied by Fevitite, manufactured by Padmaja Laboratories, Navi Mumbai, India. Epoxy, also known as polyepoxide, is a thermosetting polymer formed from reaction of an epoxide resin with polyamine hardener. All hardeners are mixtures of aliphatic polyamines, cycloaliphatic polyamines and amide amines. The materials used are shown in Fig. 1.

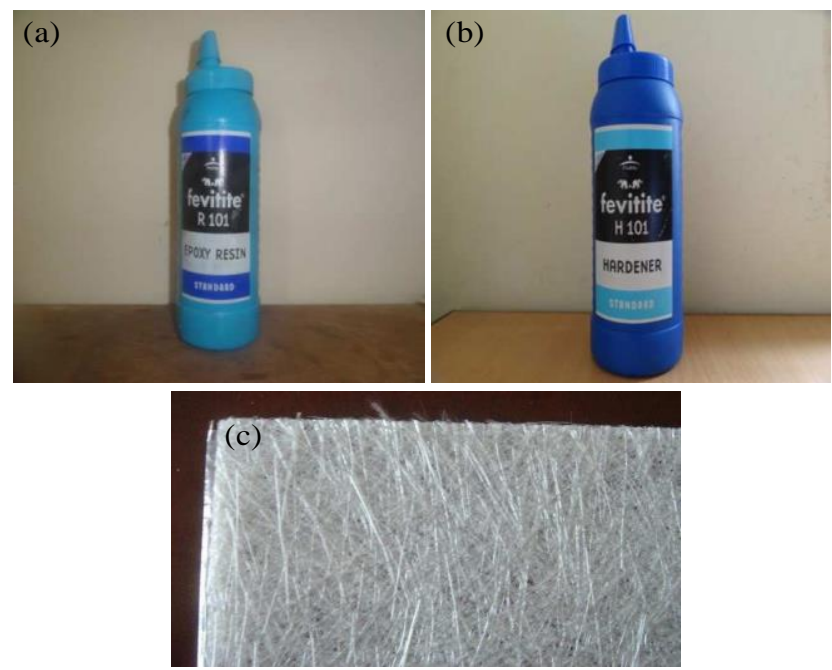

Fig. 1. Materials used in manufacturing of composites a) Epoxy Resin, b) Standard Hardener and c) Glass Fiber Mat.

\section{Fabrication of composites}

There are many composite manufacturing techniques available in industry [22-24]. Compression molding, vacuum molding, pultruding, and resin transfer molding [25] are few options. The hand lay-up [26] manufacturing process is one of the common techniques to combine resin and fabric components. This process allows manual insertion of fiber reinforcement into a single-sided mould, where resin is then forced through fiber mats using hand rollers. A primary advantage to the hand lay-up technique is its ability to fabricate very large, complex parts with reduced manufacturing times. Additional benefits of hand lay-up process are simple equipment and tooling that are relatively less expensive than other manufacturing processes. All composite specimens were manufactured using hand lay-up process.

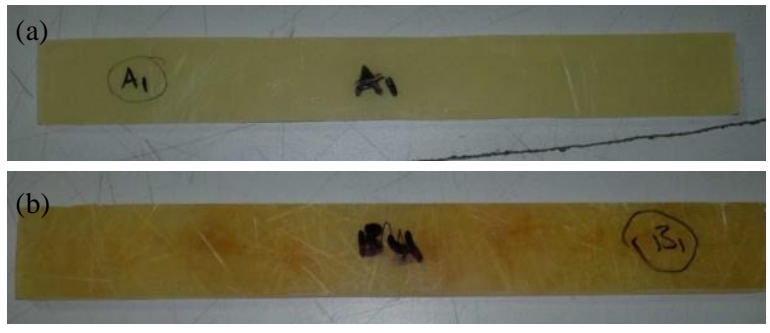

Fig. 2. (a) Pure epoxy and (b) glass fiber reinforced composite.

\section{Test specimens}

The composite specimens were produced in rectangular size as per ASTM standards ASTM D638 (165x19x4 mm) 
for tensile tests and ASTM D790 (130x12x4 mm) for flexural tests as shown in Fig. 2.

\section{Test apparatus and procedure}

All experimental tests were carried out at central institute of plastic engineering and technology (CIPET) PANIPAT.

Tensile test: The tensile tests were conducted on Autograph Machine. These tests were carried out on rectangular specimens $(165 \times 19 \mathrm{~cm})$ at room temperature. Specimens were placed in the grips and were and pulled until failure. The test speed was $5 \mathrm{~mm} / \mathrm{min}$ as per ASTM D638 and an extensometer/strain gauge was used to determine the elongation and tensile modulus. Fig. 3 shows the tensile testing apparatus for the various composites.

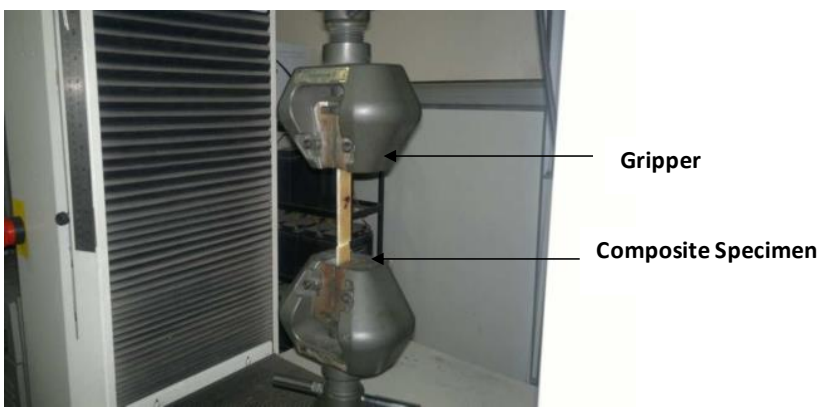

Fig. 3. Tensile testing on autograph machine.

Flexural test: Flexural testing was carried on rectangular specimens $(130 \times 12 \mathrm{~mm})$ of composite using Autograph Machine at ambient temperature according to the procedure described in ASTM D- 790. The test was initiated by applying the load on the specimen at the specified rate. The deflection was measured by a gauge under the specimen in contact with it in the center of the support span. Fig. 4 shows the flexural testing apparatus for the various composites.

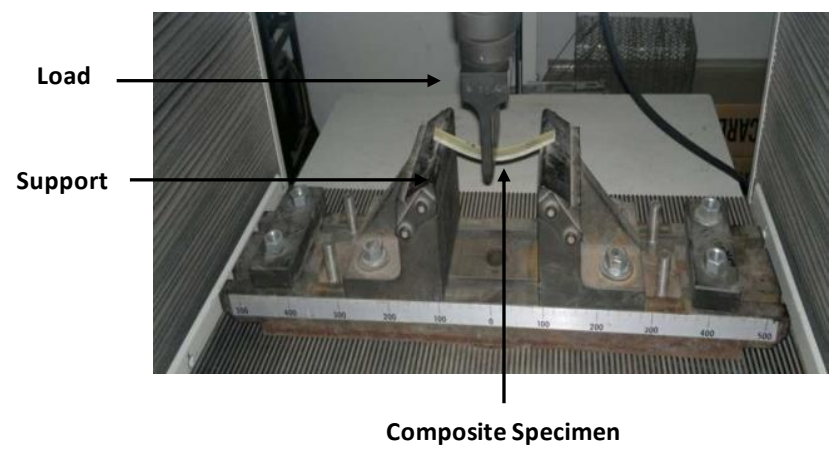

Fig. 4. Flexural (three point bending) test on autograph machine

\section{Results and discussion}

\section{Tensile strength}

Ultimate tensile strength (UTS) often shortened to tensile strength (TS) or ultimate strength is the maximum stress that a material can withstand while being stretched or pulled before necking, which is when the specimen's crosssection starts to significantly contract. It is an intensive property; therefore its value does not depend on the size of the test specimen, it is dependent on other factors, such as the preparation of the specimen, the presence of surface defects, and the temperature of the test environment and material. The tensile strength of a fiber reinforced composite (Tsc) depends on the bonding between the fibers and the matrix. The function of the matrix is to transfer the stresses to the load bearing fibers. The tensile strength for any composite specimens is given by rule of mixtures, which is represented by equation 1 [27].

$$
T_{s c}=V_{f} \sigma_{f}+V_{m} \sigma_{m}
$$

where, $\mathrm{T}_{\mathrm{sc}}$ : tensile strength of the composite.

$\sigma_{f}:$ average stress in the fibers

$\sigma_{m}$ : average stress in the matrix

$\mathrm{V}_{\mathrm{m}}$ : volume fraction of the matrix

$\mathrm{V}_{\mathrm{f}}$ : volume fraction of the fibers
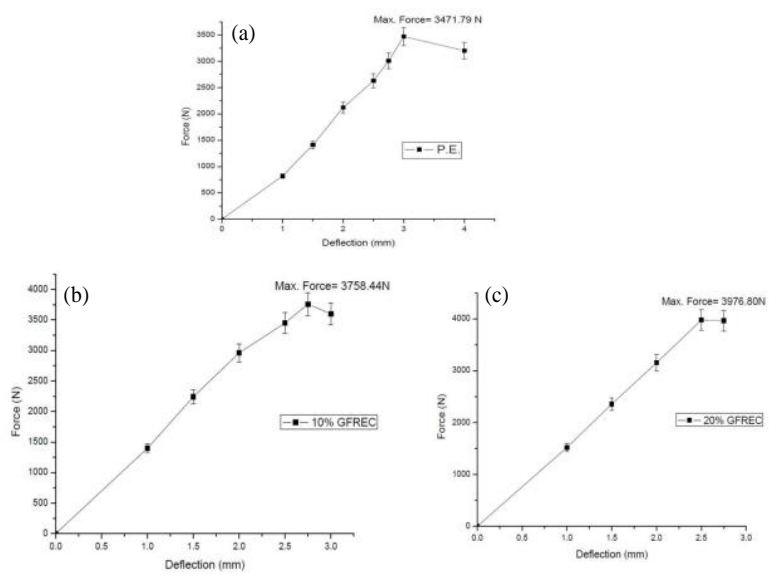

Fig. 5. Force v/s deflection curve for (a) P.E., (b) GFREC 10\%wt, (c) GFREC $20 \%$ wt fraction for tensile test.

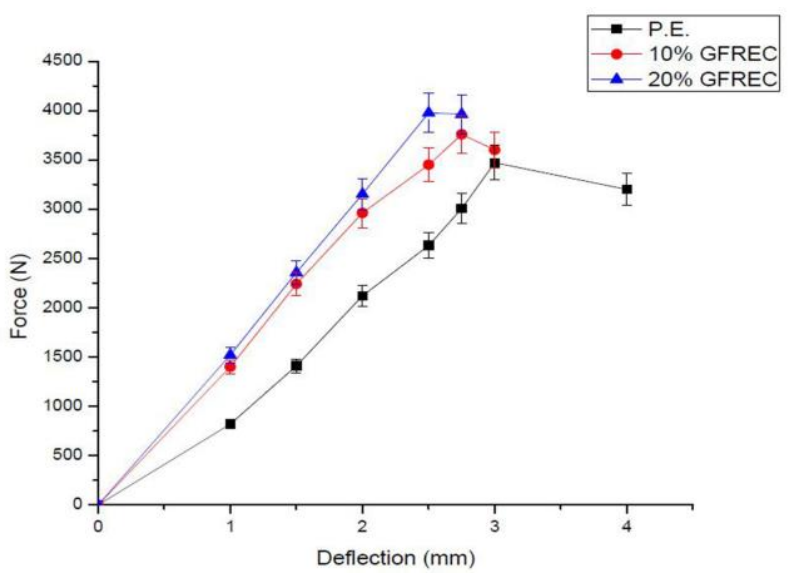

Fig. 6. Comparison of force v/s deflection plot for (P.E, GFREC 10\% and GFREC $20 \%$ ) tensile test.

The characterization of the composites reveals that the content of fiber has significant effect on the mechanical properties. The force $\mathrm{v} / \mathrm{s}$ deflection graphs were plotted using tensile test for P.E, GFREC $10 \%$ weight fraction and GFREC 20\% weight fraction shown in Fig. 5(a-c). The comparison of force $\mathrm{v} / \mathrm{s}$ deflection for all the specimens of tensile tests show in Fig. 6, which revealed that maximum 
force carrying capacity increase with the increasing in fiber content in epoxy matrix. The experimental results of tensile tests of composites with different weight fraction of reinforcement are presented in Table $\mathbf{1}$.

Table 1 Experimental results for tensile test

\begin{tabular}{ccccc}
\hline Composites & $\begin{array}{c}\text { Max. Force } \\
\text { N }\end{array}$ & $\begin{array}{c}\text { Tensile Strength } \\
\text { MPa }\end{array}$ & $\begin{array}{c}\text { Strain } \\
\text { \% }\end{array}$ & $\begin{array}{c}\text { Break_force } \\
\text { N }\end{array}$ \\
\hline P.E & 3471.79 & 44.1607 & 6.742 & 3460.78 \\
GFREC 10\%wt & 3758.44 & 47.7994 & 5.231 & 3758.44 \\
GFREC 20\% wt & 3976.80 & 50.5670 & 1.574 & 3962.73 \\
\hline
\end{tabular}

The tensile strength values obtained for various composite specimens are presented in Fig. 7 the tensile strength of the composite increases with increase in fiber content because the glass fibers are the main load carrying members and matrix acts as stress transfer medium and when the load increase maximum stress it taken up by the fibers.

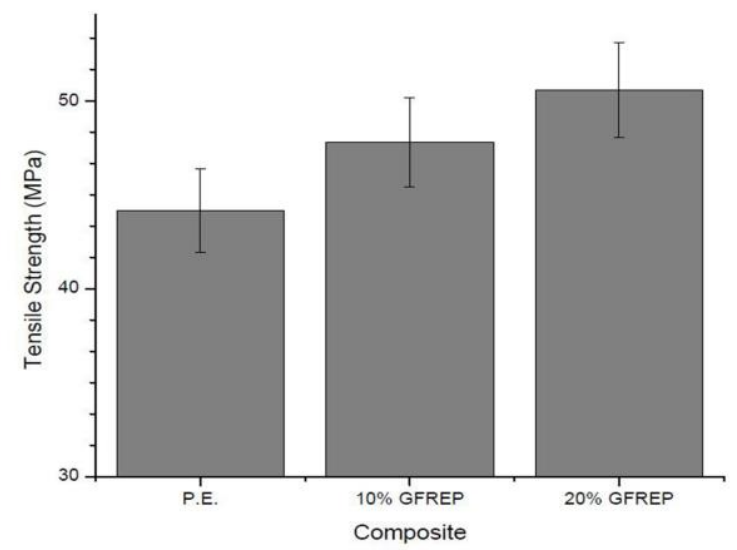

Fig. 7. Effect of glass fiber content on tensile strength of various composites.

\section{Flexural strength}

Flexural strength is also known as modulus of rupture, bends strength, or fracture strength, which is mechanical parameter of materials. It is defined as a material's ability to resist deformation under bending loads. The transverse bending test is most frequently employed, in which a rod specimen having either a circular or rectangular crosssection is bent until fracture occurs using a three point flexural test technique. The flexural strength represents the highest stress bearing capacity of the material at its moment of rupture. It is measured in terms of stress, which is given by equation 2 [27] for a rectangular sample under a load in a three-point bending test,

$$
\sigma=\frac{3 F L}{2 b d^{2}}
$$

where, F, is the load $(\mathrm{N})$ at the fracture point.

$\mathrm{L}$, is the length of the support span.

$\mathrm{B}$, is width of rectangular section.

$\mathrm{D}$, is thickness of rectangular section.
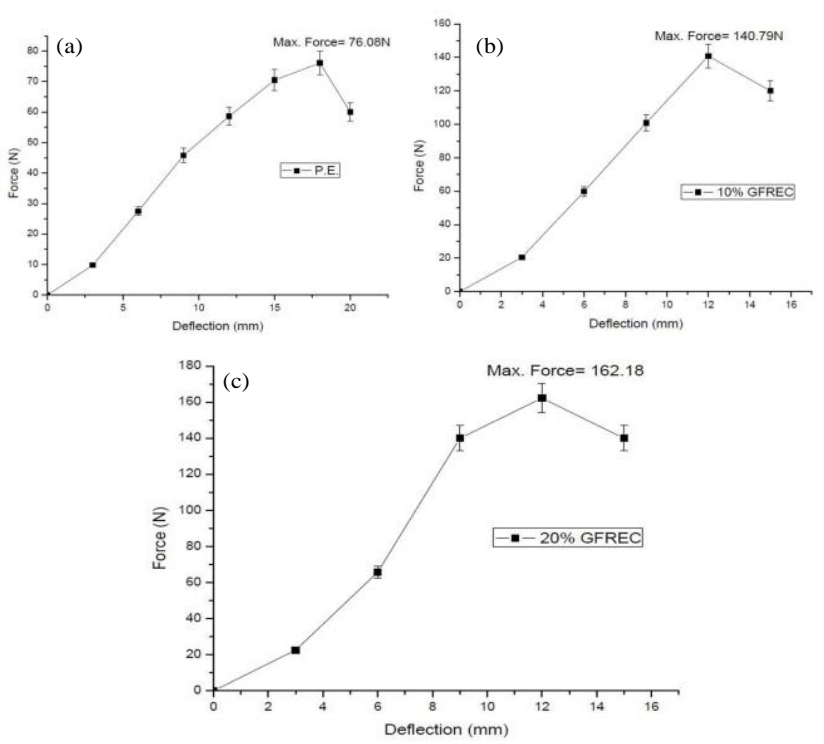

Fig. 8. Force v/s deflection curve for (a) PE, (b) GFREC 10\%wt, (c) GFREC $20 \%$ wt fraction for flexural test.

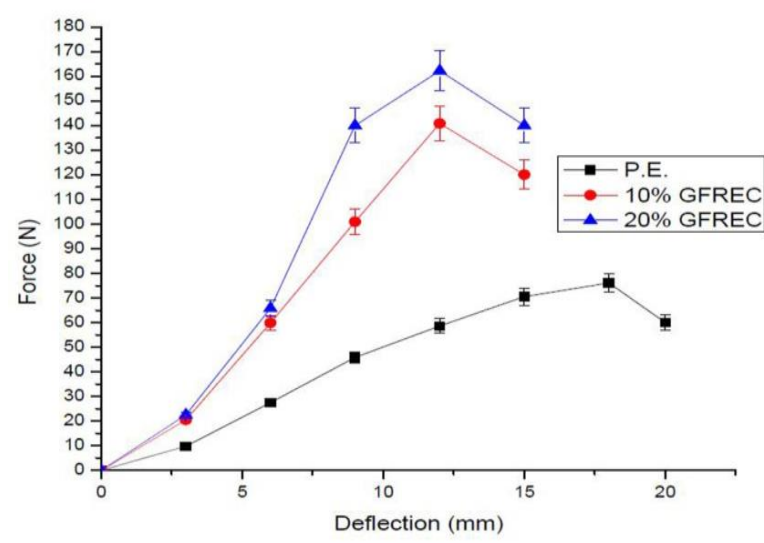

Fig. 9. Comparison of force v/s deflection plot for (P.E. , GFREC $10 \%$ and GFREC $20 \%$ flexural test).

Table 2. Experimental results for flexural test.

\begin{tabular}{cccc}
\hline Composites & $\begin{array}{c}\text { Max.Force } \\
\text { N }\end{array}$ & $\begin{array}{c}\text { Flexural Strength } \\
\text { MPa }\end{array}$ & $\begin{array}{c}\text { Break_Force } \\
\text { N }\end{array}$ \\
\hline P.E & 76.08 & 56.24 & 69.97 \\
GFREC 10\%wt & 140.797 & 109.315 & 138.688 \\
GFREC 20\%wt & 162.188 & 125.781 & 150.828 \\
\hline
\end{tabular}

From the flexural test results force v/s deflection graphs were plotted for P.E, GFREC 10\%wt and GFREC 20\%wt fraction shown in Fig. 8 (a-c). The comparisons between the flexural tests of all specimens are show in Fig. 9. The plots show that with increase in fiber content in epoxy the flexural strength also increases. The experimental results of flexural tests of composites with different weight fraction of reinforcement are presented in Table 2. The comparison of flexural strength of various composites are shown in Fig. 10, which shows that with increase in weight fraction/ content of fibers the flexural strength increases due to the increased stiffness of composites. Glass fibers are lighter in weight and are stiffer which resists bending loads. 


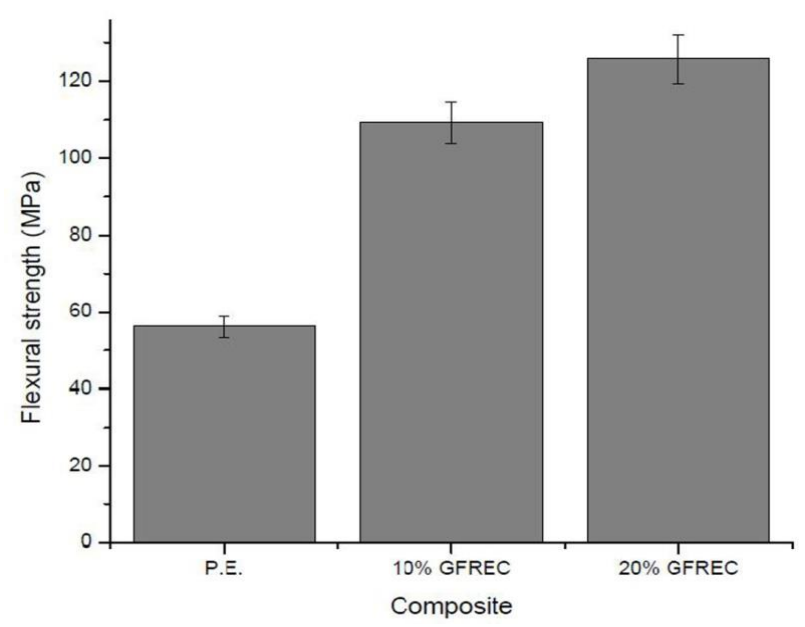

Fig. 10. Effect of glass fiber content on flexural strength of composites

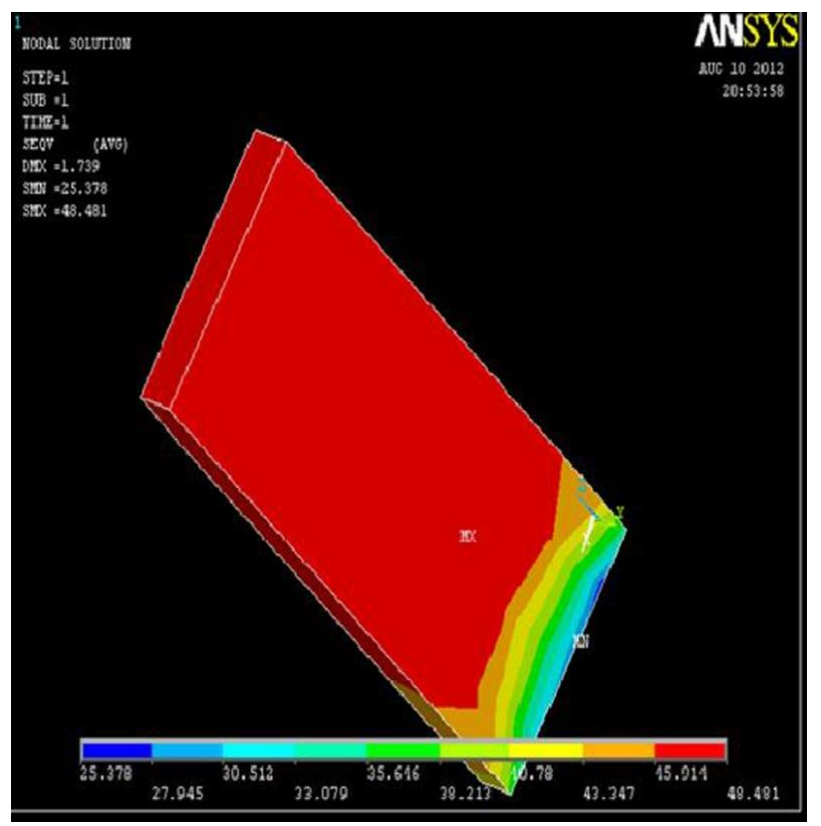

Fig. 11. Nodal solution of tensile test for GFREC 20\%wt.

\section{Finite element analysis scheme}

With the advancement of computers, finite element analysis [6] has become one of the most important tools available to an engineer for design analysis. The finite element method is one of the most general procedures for solving complex analysis problems. For performing finite element analysis the material was considered to be isotropic in nature and the boundary condition and load conditions applied were similar to the experimental condition. The element type used for ANSYS work was solid 8-node 45 [23] and the values of young modulus and poison ratio were taken from experimental results. The force $\mathrm{v} / \mathrm{s}$ deflection plots were plotted using ANSYS data and the comparisons were made with experimental results.

The nodal solution of tensile test by using ANSYS is shown in Fig. 11. The experimental results of all the specimens for tensile test were compared with ANSYS results and are shown in Fig. 12(a-c). The nodal solution of flexural tests by using ANSYS is shown in Fig. 13. The experimental flexural test results of all the specimens were compared with ANSYS results and are shown in Fig. 14(ac).
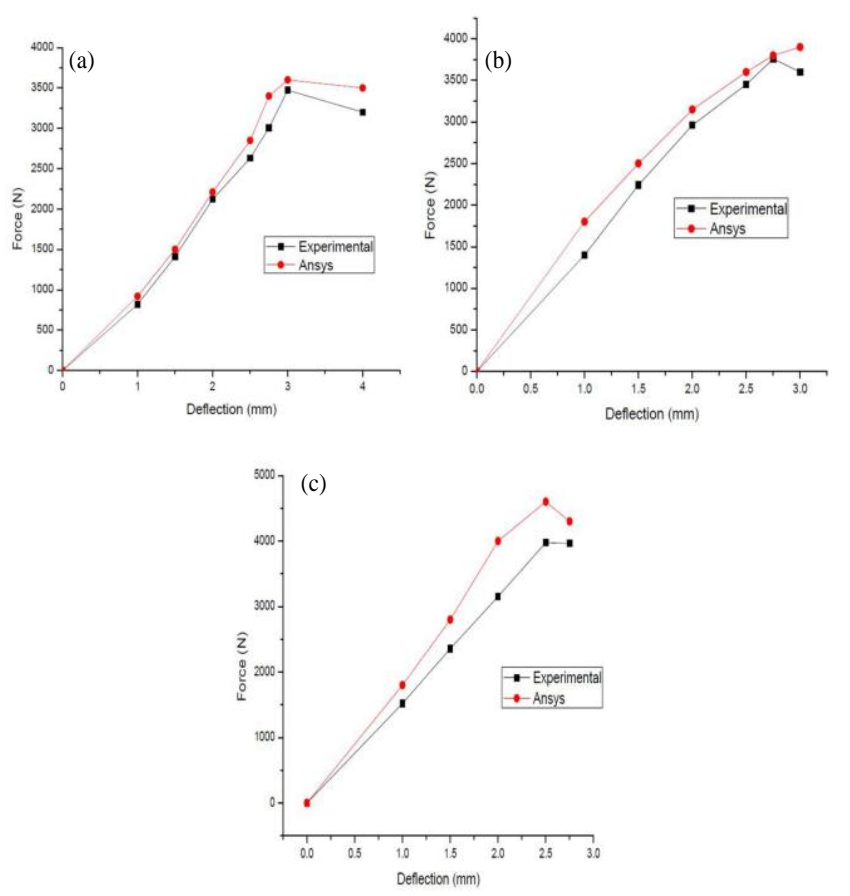

Fig. 12. Comparison of force v/s deflection curve for (a) PE, (b) GFREC $10 \%$ and (c) GFREC $20 \%$.

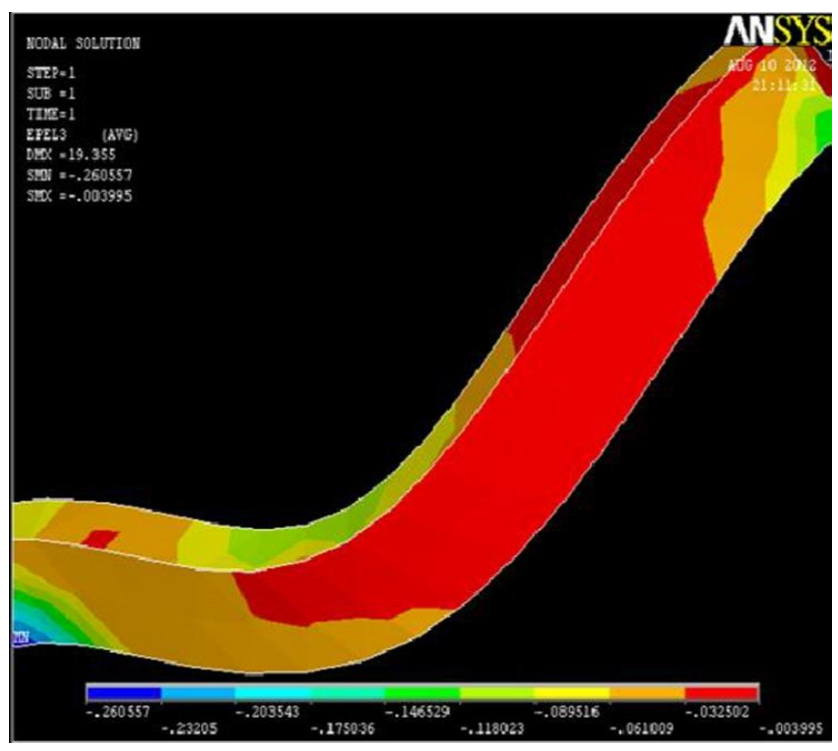

Fig. 13. Nodal solution of flexural test for GFREC $20 \%$ wt

Results revealed that tensile and flexural results for numerical analysis are better than experimental results. This deviation of results occurred due to manufacturing defects of composites like blow holes, porosity etc. Further in analysis part isotropic behavior was considered, but it is not possible to achieve isotropic behavior practically using random oriented fibers due to stress concentrations at fiber ends. 


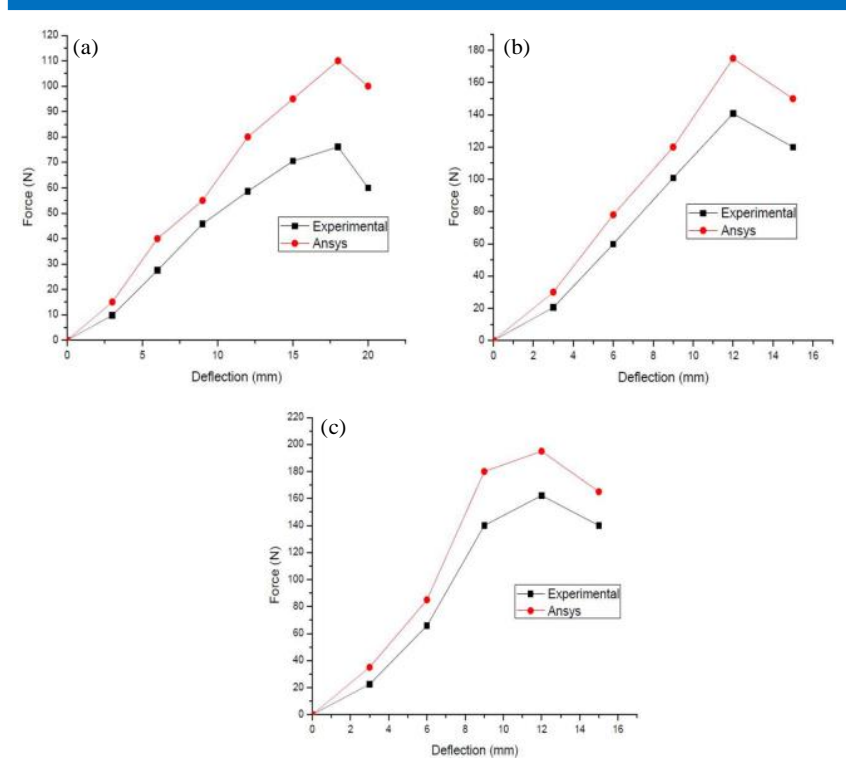

Fig. 14. Comparison of force v/s deflection curve for a) PE, b) GFREC $10 \%$ and c) GFREC $20 \%$.

\section{Conclusion}

The present investigations of mechanical behavior of glass fiber reinforced epoxy composites revealed that the tensile strength and flexural strength is greatly influenced by the fiber content/ weight fraction of reinforcement in matrix. A reinforced composite shows more tensile and flexural strength than unreinforced epoxy. With increase in $20 \%$ of weight fraction of glass fibers over pure epoxy, the tensile strength and flexural strength increased by $14.5 \%$ and $123.65 \%$. The contribution to flexural strength is more than tensile strength due to presence of glass fibers which increased the overall stiffness of composites. The value of young modulus of elasticity also increased with increase in weight fraction of material, which signifies increased strength and reduced strain. The finite element analysis of glass fiber reinforced epoxy composite has generated the detailed quantitative data about the failure morphology of the composites. For tensile tests maximum stresses are occurring at centre of specimen from where fracture starts. In flexural testing also maximum stresses are occurring at the point where load is applied and breaking starts from here. Both the results of finite element analysis and experimental analysis are in good agreement.

\section{Reference}

1. Kaw A.K.; Mechanics of composite materials, Chapter 1, CRC Press: Taylor \& Francis Group, USA, 2006, 2nd ed.

ISBN: $0-8493-1343-0$.

2. Ghassemieh, E.; Nassehi, V. Polymer Composites. 2001, 22, 528.

DOI: $10.1002 /$ pc. 10557.

3. Chandra, R.; Singh, S. P.; Gupta, K. Composite Structures. 1999, 46, 41.

DOI: $10.1016 / \mathrm{S} 0263-8223(99) 00041-0$

4. Haldar, A.K.; Singh, S.; Prince. AIP conference proceedings. 2011, 1414, 211. DOI: $10.1063 / 1.3669958$

5. Malkapuram, R.; Kumar, V.; Negi Y.S. Journal of Reinforced Plastics and Composites. 2009, 28, 1169.

DOI: $10.1177 / 0731684407087759$

6. Matter, M.; Gmur, T.; Cugnoni, J.; Schorderet, A. Computers and Structures. 2010, 88, 902.

DOI: $\underline{10.1016 / j . c o m p s t r u c .2010 .04 .008}$

7. Sun, W.; Lin, F. Journal of Thermoplastic Composite Materials, 2001, 14, 327.

DOI: $10.1106 / Y K D M-P X 8 K-N F 6 Q-L 7 F K$

8. Gilchrist, M.D.; Kinloch, A.J. Composites Science and Technology, 1996, 56, 37.

DOI: $10.1016 / 0266-3538(95) 00126-3$

9. Ascione, F.; Feo, L.; Maceri, F. Composites Part B: Engineering. 2009, 40, 97.

DOI: $10.1016 /$ j.compositesb.2008.11.005

10. Shokrieh, M.M.; Omidi, M.J. Composite Structures, 2009, 88, 595. DOI: $10.1016 /$ j.compstruct.2008.06.012

11. Haider, A.Z.; Zhao, X.L.; Riadh, A.M. Procedia Engineering, 2011, $10,2453$.

DOI: $10.1016 /$ j.proeng.2011.04.404

12. Segurado, J.; LLorca J. Mechanics of materials, 2006, 38, 873. DOI: $10.1016 / \mathrm{j} . \mathrm{mechmat} .2005 .06 .026$

13. Zhang, Y.X.; Yang, C.H. Composite Structures, 2009, 88, 147. DOI: $10.1016 / \mathrm{j} . \mathrm{compstruct} .2008 .02 .014$

14. Kabir, M.R.; Lutz, W.; Zhu, K.; Schmauder, S. Computational Materials Science, 2006, 36, 361.

DOI: $\underline{10.1016 / j . c o m m a t s c i .2005 .09 .004}$

15. Goh, K. L; Aspden, R. M; Hukin, DWL. Composite Science and Technology, 2004, 64,1091.

DOI: $\frac{10.1016 / \text { i.compscitech.2003.11.003 }}{\text {. }}$

16. Zhang, Y.; Xia, Z. CMC, 2005, 2, 213. DOI: $10.3970 / \mathrm{cmc} .2005 .002 .213$

17. Houshyar, S.; Shanks, R.A.; Hodzic, A. Express Polymer Letters, 2009, 3,2 .

DOI: $10.3144 /$ expresspolymlett.2009.2

18. Ghassemieh, E.; Nassehi, V. Polymer Composites, 2001, 22, 542. DOI: $10.1002 / \mathrm{pc} .10558$

19. Ghassemieh, E.; Nassehi, V. Advances in Polymer Technology, 2001, 20, 42 . DOI: $10.1002 / 1098-2329(200121) 20: 1<42:: A I D-D V 1003>3.0 . C O ; 2-$ F

20. Horsta, J. J.; Salienkob, N. V.; Spoormaker, J. L. Composites Part A, 1998, 29, 525. DOI: $10.1016 / \mathrm{S} 1359-835 \mathrm{X}(97) 00125-5$

21. Caporale, A.; Luciano, R.; Sacco, E. Computers and Structures, 2006, 84, 2200.

DOI: $10.1016 / j . c o m p s t r u c .2006 .08 .023$

22. Jones, M. R.; Mechanics of Composite Materials, Chapter 1.4., Applications of Composite Materials, Edwards Brothers, 1998, Ann Arbor, MI,.

ISBN: $13978-1560327127$

23. Naik, K.N. Woven Fabric Composites, Introduction, Technomic Publishing Company Inc., Pennsylvania (1994).

24. Chou, T.W.; Ko, K. F. Textile structural composites, Introduction to textile structures and their behavior, Elsevier Science Publishing Company, 1989, New York.

25. Kendall, K.N.; Rudd, C.D.; Owen, M.J.; Middleton, V. Composites Manufacturing, 1992, 3, 235.

DOI: $10.1016 / 0956-7143(92) 90111-7$

26. Davim J. P., Reis P., António C. C. Composites Science and Technology, 2004, 64, 2, 289.

DOI: $10.1016 / \mathrm{S} 0266-3538(03) 00253-7$

27. Sathishkumar, T.P.; Navaneethakrishnan, P.; Shankar, S. Composites Science and Technology, 2012, 1183.

DOI: $10.1016 /$ j.compscitech.2012.04.001

\section{Advanced Materials Letters}

Publish your article in this journal

ADVANCED MATERIALS Letters is an international journal published quarterly. The journal is intended to provide top-quality peer-reviewed research papers in the fascinating field of materials science particularly in the area of structure, synthesis and processing, characterization, advanced-state properties, and
applications of materials. All articles are indexed on various applications of materials. All articles are indexed on various
databases including DOAJ and are available for download for free. The manuscript management system is completely electronic and has fast and fair peer-review process. The journal includes review articles, research articles, notes, letter to editor and short communications.

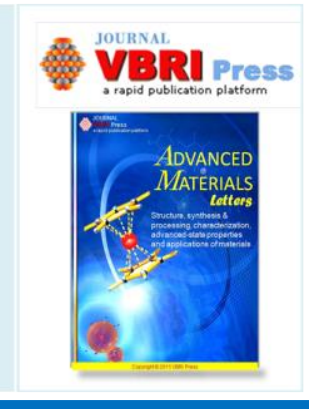

